\title{
Bovine Hydatidosis in Eastern Part of Ethiopia
}

\author{
Miheret Mulatu, Biruk Mekonnen, Habtamu Tassew and Ashwani Kumar* \\ Department of Veterinary Medicine, College of Veterinary Medicine, Mekelle University, \\ Mekelle, Ethiopia (*ashwanivet126@yahoo.com)
}

\begin{abstract}
A cross-sectional study was conducted on bovine hydatidosis from November 2010 to March 2011 with the aims of investigating its occurrence, risk factors and economic losses in Dire Dawa municipality abattoir. The study revealed $20.05 \%$ occurrence of hydatidosis based on the postmortem examination of 1536 cattle. Age related infection was significant as older animals were more infected $\left(\mathrm{P}<0.05, \mathrm{x}^{2}=27.496\right)$. Among the lungs, liver, heart, spleen and kidneys examined in each carcass, the cysts were distributed in the lungs and livers only. Out of 1852 cysts, $1340(72.3 \%)$ were found in liver while512 $(27.7 \%)$ in lungs. Five hundred and twenty $(53.94 \%)$ of 964 hydatid cysts were small, while268 (27.80\%) medium and $176(18.25 \%)$ large. These cysts were further characterized as fertile $(80.08 .7 \%)$, sterile (17.3\%) and calcified $(2.85 \%)$ and $53.7 \%$ of fertile cysts were viable. Based on the study, the direct economic loss was estimated to be 23,876 Ethiopian Birrs. Presence of hydatid cysts in edible organs has great public health significance as consumption of undercooked/raw meat is still in practice in many parts of Ethiopia.
\end{abstract}

Keywords: Abattoir, Bovine, Carcass, Cysts, Hydatidosis, Eastern Ethiopia.

\section{INTRODUCTION}

Hydatidosis caused by the metacestode of Echinococuss granulosus is a widely spread parasitic zoonosis that had caused public health problems in many countries (Ansari-Lari, 2005). Mechanical dysfunction of organs due to the cysts and anaphylaxis, as a consequence of the cyst burst and releasing fluid, is a serious manifestation in human (ESAP,1995).Even though hydatidosis has been known and documented in Ethiopia as early as 1970, it is still the major cause of organ condemnation in most Ethiopian abattoirs and lead to huge economic losses to the livestock industry (Hagos, 1997).Several reports had indicated that hydatidosis is widely prevalent in livestock population of various regions of Ethiopia (Kebede et al., 2009) but its status was not known in Dire Dawa which is a city in eastern part of Ethiopia where the hygienic conditions are poor and backyard slaughtering of domestic animals, raw beef consumption and feeding stray dogs with condemned organs are common practices. Keeping in view the public health significance of hydatidosis in cattle, the present study was undertaken to elucidate its prevalence, risk factors and economic significance in cattle slaughtered at Dire Dawa municipality abattoir, Ethiopia. 


\section{MATERIALS AND METHODS}

The study was conducted in Dire Dawa town belonging to eastern part of Ethiopia. The area has an average annual rain fall of $604 \mathrm{~mm}$ and a mean daily temperature of $25.4^{\circ} \mathrm{C}$. Agriculture is the main occupation and extensive system of livestock management predominate the area with dogs commonly used for control and guarding of herds of cattle and flocks of goats.

A cross sectional study design was used to examine the prevalence of bovine hydatidosis and its economic significance from November 2010 to March 2011. During the period of study, three visits per week were made purposively out of 5 slaughter days in a week. Out of a total of 3120 cattle slaughtered at Dire Dawa municipality abattoir during the study period, 1536 indigenous zebu cattle were inspected. Age wise, the selected animals were divided into young (352) of less than 5 years of age and adult (1184) of 5 or above years. Body scores of animals were poor in 372, medium in 956 and good in 208 cattle at the time of ante-mortem examination. All the examined animals were marked for identification. Post mortem examination was made through inspection, palpation and systematic incision of internal organs such as lung, liver, heart, spleen and kidney (FAO, 1994) and the organ distribution and rate of infection of hydatidosis were recorded. The total number of mature cysts obtained per organ was counted and the cyst burden per organ was also recorded. The cysts were subjected to systematic size measurement (diameter) and classified as small, medium and large cysts and were subjected to fertility and sterility tests at regional laboratory.

\subsection{Examination of cysts for fertility and viability}

Based on the presence or absence of brood capsules containing protoscolices in hydatid fluid, cysts were identified and classified as fertile and infertile according to the method described by Macpherson (1985). Infertile cysts were further classified as sterile (fluid filled cyst without protoscoleces) or calcified (Soulsby, 1982). To test the viability, the cyst wall was penetrated by a needle and opened and the contents were examined microscopically (40x) for the amoeboidlike peristaltic movements of protoscoleces according to the standard procedure (Smyth and Barrett, 1980). In doubtful cases, a drop of $0.1 \%$ aqueous eosin solution was added to equal volume of protoscolices on a microscope slide with the principle that viable protoscolices completely or partially exclude the dye while the dead ones take it up (Smyth and Barrett, 1980;Macpherson,1985). 


\subsection{Economic Loss}

To study the economic losses due to hydatidosis, only direct losses were considered and the calculation was based on condemned organs (liver, lungs). In calculating cost of condemned edible organs, 15 different meat sellers, 4 meat inspectors and 10 residents were interviewed randomly to establish the price per unit organ and the average organ price was determined and this price index was used to calculate the loss (Yifat Denbarga, 2011). The economic significance of the parasite was determined by multiplying the average retail market price of the organs by the number of condemned organs.

\subsection{Data Analysis}

The data obtained was coded in Microsoft excel and subjected to descriptive statistics and chisquare in order to assess the magnitude of the difference of comparable variables using SPSS version 17.0 software. Statistically significant association between variables is considered to exist if the $\mathrm{p}$-value is less than 0.05 .

\section{RESULTS}

\subsection{Occurrence of hydatidosis}

The occurrence of hydatidosis was $20.1 \%$ as 308 of 1536 cattle were having hydatid cysts. Infection rate of the disease was correlated with the age, sex, and body condition of the animals. Chi square test showed that prevalence was significantly different $(\mathrm{p}<0.05)$ among young $(32 / 308 ; 10.38 \%)$ and adult $(276 / 308 ; 89.61 \%)$ cattle and among poor(144/308; 46.75\%), medium $(124 / 308 ; 40.25 \%)$ and good $(40 / 308 ; 12.98 \%)$ body scores of animals.

\subsection{Characterization of hydatid cysts}

Among the 1852 hydatid cysts observed, 1340 were in liversand512 in lungs. Of these, 520(28.07\%), 268(14.47\%) and 276(14.92\%) and 788(42.54\%) were small, medium, large and calcified respectively. Nine hundred and sixty eight of these 1852 cysts were subjected to fertility test which revealed $772(79.75 \%)$ as fertile, $168(17.35 \%)$ sterile and $28(2.89 \%)$ calcified. Viability test proved $520(53.71 \%)$ of968 cysts as viable. Organ wise fertility of cysts was $36.6 \%$ from liver and $43 \%$ from the lungs while viability of these fertile cysts was $27.6 \%$ and $26.1 \%$ respectively. 


\subsection{Economic loss due to organ condemnation}

180 lungs and 232 livers of cattle were condemned due to the presence of hydatid cysts. Taking the average market price of each liver and lung as 68 and 18 Ethiopian Birrs respectively, the economic loss at a single abattoirat Dire Dawa, Ethiopia was estimated at165876Ethiopian Birr (ETB) which includes 8100 Birrs on account of condemnation of lungs and15, 7776 due to liver condemnation. $(1 \mathrm{USD}=17.53 \mathrm{ETB})$.

\section{DISCUSSION}

Prevalence of hydatidosis varies from country to country or even within the country and has been reported by various researchers from developing countries under extensive production system (Gracey et al., 1999). The present finding of $20.1 \%$ prevalence of bovine hydatidosis at Dire Dawa municipal abattoir is almost in agreement with that of Azlaf and Dakkak (2006) and Kebede et al. (2009) who reported $22.98 \%$ in Morocco and $22.1 \%$ prevalence in Tigray municipality abattoir respectively. But this percentage is slightly higher than $16 \%$ prevalence of bovine hydatidosis reported at Wolayta Sodo municipality abattoir (Nigatu et al., 2009) and15.2\% in Birre Sheleko and Dangila municipality abattoir (Kebede et al., 2006). However, as per literature, bovine hydatidosis has been reported even at a prevalence rateas high as $31.44 \%$ in Jimma municipality abattoir, south west, Ethiopia (Tolossa et al., 2009) and 48.7\% in Nagorgoro district of Arusha region, Tanzania (Ernest et al.,2008). The discrepancy might be attributed to the strain difference of E. granulosus that exist in different geographical situations and other factors like difference in culture, social activity and attitude to dog in different regions(Arene, 1995). However, the variability in prevalence demonstrated in areas having similarity with the present study area may mainly be due to different stages of infection in the population at the time of examination and sampling strategy that was employed.

In this study, there was a significant difference $(\mathrm{p}<0.05)$ in prevalence of bovine hydatidosis among young and adult and different body conditions of the cattle. Adult animals having a higher prevalence $(276 / 308 ; 89.6 \%)$ may be due to their longer exposure to infection and to lower immunity to combat infection and these results are concurrent with that of other studies in Ethiopia (Fikre, 1994; Hagos, 1997). Animals having poor body conditions were found to have higher cysts burden which can be explained due to the retarded growth, weight loss and moderate to severe infection in such animals as described by Polydorous (1981). 
Among the organs examined, the cysts were found only in the liver and lungs which is not unusual. The liver and lungs possess greater capillaries that act as partial barriers for the ingested hexachant embryos taking the portal vein route and primarily negotiate the hepatic and pulmonary system sequentially before any other peripheral organ invasion (Estagil and Tuzer, 2007). Even though the liver had a higher rate (72.3\%) of cysts distribution but most of them $(42.52 \%)$ were calcified. In contrast to this, lungs were not having calcified cysts which is in agreement with other studies in cattle in Ethiopia (Endrias et al., 2008). Moreover, there was a significant difference $(\mathrm{p}<0.05)$ between cyst size and organs as the higher number of large sized cysts harbored the lungs which may be due to their relatively softer consistency. The high proportion of small cysts may indicate infection of animals as a result of heavy rain fall and continuous grazing in the past rainy seasons or due to immunological response of the hosts which might have reduced the expansion of cyst size. Moisture and rain fall favors the survival of eggs of E. granulosus species and at the same time eggs may get chance to be disseminate by flood (Hagos, 1997).

Prevalence and fertility of hydatid cysts in various organs of cattle are important indicators of potential sources of infection to perpetuate the disease in dogs. In this study, the percentage of fertile cysts recovered was $79.7 \%$ (772/968) which is comparable to the report of $70 \%$ fertility in Great Britain and lower than to $96 \%$ in South Africa and 94\% in Belgium (Arene, 1995). The variation in fertility rate in different geographical zones could be due to the difference in strain of E. granulosus (Arene, 1995). Fertility rate among the organs was higher in the lungs (42.9\%) than in livers (36.7\%), which is in agreement with other study in cattle in Ethiopia (Tolossa et al., 2009). This variation might be due to the difference between tissue resistances of organs.

The financial loss of $\$ 23,876$ in Dire Dawa municipal abattoir during the six months period of study is a huge loss for a country like Ethiopia, where the per capita income is $<1$ USD (Togerson and Budke, 2003). This financial loss on account of hydatidosis from the city of Dire Dawa is an underestimate and will still be higher if the cattle slaughtered at the backyards are taken into account. The economic loss as per this study is lower than the loss of 25,608 Ethiopian birr in Tigray region of northern Ethiopia reported by Kebede et al. (2009).The difference in economic loss in various regions is possible because of the variation in the prevalence of the disease, mean annual slaughtered cattle in different abattoirs and variation in the retail market price of organs. 


\section{CONCLUSION}

Bovine hydatidosis is a public health risk and causes considerable economic loss via decreasing livestock production and condemnation of offals in slaughter houses. The abattoir survey evidence of the present investigation showed that hydatidosis is prevalent in cattle population of Dire Dawa municipality area located in Eastern Ethiopia and may be a public health concern. Factors like presence of more stray dogs that visits the abattoir ground and fed on condemned organs, low public awareness about hydatidosis and backyard slaughtering favors the disease transmission in this area. Measures like, prohibition of backyard slaughter, proper disposal of condemned offals, regular deworming of dogs and disease education to farmers, animal attendants, abattoir workers and butchers, are recommended.

\section{ACKNOWLEDGEMENT}

The authors extend their thanks to Department of Veterinary Medicine, College of Veterinary Medicine, Mekelle University, Mekelle, Ethiopia for providing necessary facilities for the research work.

\section{REFERENCES}

Ansari-Lari, M. 2005. A retrospective survey of hydatidosis in livestock in Shiraz, Iran, based on abattoir dataduring 1999-2004.Veterinary Parasitology,133:119-123.

Arene, FA.I. 1995. Prevalence of hydatidosis in domestic livestock in the Niger Delta.Tropical Animal Health Production, 17:3-5.

Azlaf, R \& Dakkak, A. 2006. Epidemiological study of the cystic echinococcosis inMorocco. Veteterinary Parasitology, 137: 83 - 93.

Endrias, Z., Yechale, T \& Assefa, M. 2008. Bovine hydatidosis in Ambo municipality abattoir, DVMthesis, Jimma University, Jimma, Ethiopia (unpubl.).

Ernest, E., Nonga, H.E, Kassuku, A.A \& Kazwala, R. R. 2008. Hydatidosis of slaughtered animals in Ngorongoro district of Arusha region, Tanzania. Tropical AnimalHealth Production,DOI 10.1007/s11250-008-9298-z.

ESAP. 1995. Ruminants livestock development strategy.Ethiopian Society of Animal Production,Addis Ababa Proceedings, 3(1-2): 1 . 
Esatgil, M.U \& Tuzer, E., 2007. Prevalence of hydatidosis in slaughtered animals in Thrace, Turkey.Turkiye Parazitoloji Dergisi, 31: 41 - 45.

FAO, 1994. Guidelines for Echinococcosis surveillance, prevention and control. FAO, Rome, No. 29, 147p.

Fikre, Lobago, 1994. Echinacoccosis / hydatidosis in Konso/ southern Ethiopia: assessment trail of its prevalence, economic and public health importance. DVM thesis, Addis Ababa University, Faculty Veterinary Medicine, Debre-Zeit, Ethiopia.

Gracey, J.F., Collins, D.S \& Huey, R.J., 1999. Meat 308 Hygiene, $10^{\text {th }}$ ed. W.B.Saunders Company Ltd., London.

Hagos, Yihdego, 1997. Hydatidosis: Prevalence and economic impact in bovine at Mekelemunicipal abattoir, zoonosis and infection in dogs. DVM thesis, Addis Ababa University, Faculty of Veterinary Medicine,Debrezeit, Ethiopia (unpubl.)..

Kebede W., Hagos A., Girma Z \& Fikre, L. 2006. Echinococosis hydatidosis and its prevalence, economic and public health significance in Tigray region, North Ethiopia.Tropical Animal Health Production, DOI 10.1007/s11250-008-9264-9.

Kebede, W., Hagos, A., Girma, Z \& Fikre, L., 2009. Echinococcosis/hydatidosis and its prevalence, economic and public health significance in Tigray region. Tropical Animal Health and Production, 41(6):865-871, DOI:10.1007/s11250-008-9264-9.

Macpherson, L.N.L. 1985. Epidemiology of hydatid disease in Kenya. A study of domestic intermediate hosts in Masaialand, Transactions of the Royal Society of Tropical Medicine and Hygiene, 79:209-217.

Nigatu Kebede., Habtamu Mekonnen., Abebe Wossene \& Getachew Tilahun. 2009. Hydatidosis of slaughtered cattle in Wolaita Sodo Abattoir, southern Ethiopia.Tropical Animal Health Production, 41: 629-633, DOI: 10.1007/s11250-9234-2.

Polydorou, F. 1981. Animal Health and Economics: Case Study of Echinococcosis with a reference to Cyprus. Bull. off. int. des epiz.,93:981-1992.

Smyth, J.D \& Barrett, N.J. 1980. Procedure of testing the viability of human hydatid cyst following surgical removal, especially after chemotherapy. Transactions of the Royal Society of Tropical Medicine and Hygiene,74: 649-652.

Soulsby, E.J. 1982. Helminthes, Arthropods and Protozoa of Domestic Animals $7^{\text {th }}$ ed, Lea and Tebiger, Philadelphia, USA, 123p. 
Togerson, P. R \& Budke, C.M., 2003. Echinococcosis - an international public health challenge: a review. Research in Veterinary Science, 74: 191 - 202.

Tolosa, T., Tigre, W., Teka, G \& Dorny, P. 2009. Prevalence of bovine cysticercosis and hydatidosis in Jimma municipal abattoir, South West Ethiopia. Onderstepoort Journal of VeterinaryResearch, 76:323-32.

Yifat Denbarga., Gedefaw Demewez \& Desie Sheferaw. 2011. Major Causes of Organ condemnation and financial significance of cattle slaughtered at Gondar Elfora Abattoir, Northern Ethiopia. Global Veterinaria,7: 487-490. 